\title{
Dementia Long-Term Care Policy Options for Family Caregivers and Medicare
}

Regina A. Shih 
For more information on this publication, visit www.rand.org/pubs/testimonies/CT457.html

\section{Testimonies}

RAND testimonies record testimony presented or submitted by RAND associates to federal, state, or local legislative committees; government-appointed commissions and panels; and private review and oversight bodies.

Published by the RAND Corporation, Santa Monica, Calif.

(C) Copyright 2016 RAND Corporation

RAND $\mathbb{R}$ is a registered trademark.

\section{Limited Print and Electronic Distribution Rights}

This document and trademark(s) contained herein are protected by law. This representation of RAND intellectual property is provided for noncommercial use only. Unauthorized posting of this publication online is prohibited. Permission is given to duplicate this document for personal use only, as long as it is unaltered and complete. Permission is required from RAND to reproduce, or reuse in another form, any of its research documents for commercial use. For information on reprint and linking permissions, please visit www.rand.org/pubs/permissions.html. 


\section{Testimony of Regina A. Shih ${ }^{1}$ \\ The RAND Corporation ${ }^{2}$ \\ Submitted to the Committee on Finance \\ Subcommittee on Health Care \\ United States Senate}

Dementia Long-term Care Policy Options for Family Caregivers and Medicare

July 13,2016

$\mathrm{I}$

n 2013, my colleagues at RAND published an estimate of the cost of dementia to millions of families and the United States more broadly, reporting it to be the most costly condition in America. ${ }^{3}$ The team found that the vast majority of dementia costs are attributable to longterm services and supports (LTSS), rather than medical care. The number of Americans who will need LTSS is expected to double by the year 2050. As the nation's population grows grayer, the costs of dementia LTSS will only soar.

Following RAND's landmark research estimating the extraordinary monetary costs of dementia, RAND researchers challenged themselves to answer the question: "What can be done about this?" I led a team that interviewed key representatives of national, state, and local stakeholder groups. Their views, combined with research on existing national dementia and longterm care reports, were evaluated to identify policy options that have the greatest impact on improving dementia LTSS. This policy evaluation was the first to examine promising LTSS policy solutions specifically for those living with Alzheimer's and other related dementias (referred to hereafter as dementia) and culminated in the RAND report, Improving Dementia Long-Term Care: A Policy Blueprint. ${ }^{4}$

\footnotetext{
${ }^{1}$ The opinions and conclusions expressed in this testimony are the author's alone and should not be interpreted as representing those of the RAND Corporation or any of the sponsors of its research.

2 The RAND Corporation is a research organization that develops solutions to public policy challenges to help make communities throughout the world safer and more secure, healthier and more prosperous. RAND is nonprofit, nonpartisan, and committed to the public interest.

${ }^{3}$ Michael D. Hurd, Paco Martorell, Adeline Delavande, Kathleen J. Mullen, and Kenneth M. Langa, "Monetary Costs of Dementia in the United States," New England Journal of Medicine, Vol. 369, No. 14, 2013, pp. 1326-1334.

${ }^{4}$ Regina A. Shih, Thomas W. Concannon, Jodi L. Liu, and Esther M. Friedman, Improving Dementia Long-Term Care: A Policy Blueprint, Santa Monica, Calif.: RAND Corporation, RR-597, 2014.
} 
To inform today's subcommittee hearing on the impact of Alzheimer's disease on families and Medicare, I present the following statement for the record that integrates key findings from RAND's dementia LTSS policy blueprint and other relevant research publications.

\section{Costs of Dementia}

In a study published in the New England Journal of Medicine, my RAND colleagues reported that the costs of care for seniors in the United States with dementia are expected to more than double by $2040 .{ }^{5}$ In that study, the RAND team estimated that about 9.1 million people ages 70 and older will be suffering from Alzheimer's disease or another dementia by 2040. That study estimated that in 2010, Americans spent $\$ 109$ billion for dementia care purchased in the marketplace, like skilled nursing facilities. When informal care provided by family members or others outside of institutional settings is factored in, the total cost of caring for individuals with dementia in 2010 grew to between $\$ 159$ and \$215 billion.

As the U.S. population ages in the coming decades, we can expect those costs to continue to escalate. Even if dementia's prevalence stays at the current rate and the cost of care does not rise, RAND's research showed that by 2040 , total costs will have soared to as high as $\$ 511$ billion. $^{6}$ The vast majority of costs associated with dementia among those ages 70 or older are attributable to LTSS, rather than medical services. Unfortunately, the LTSS system has typically not been well aligned with the needs of persons with dementia.

\section{The Current State of Dementia Long-Term Services and Supports}

The costs of LTSS for persons with dementia are high, and they increase sharply as cognitive impairment worsens. LTSS can be provided by formal or informal caregivers. According to RAND estimates, the expense of in-home assistance provided by families accounts for approximately 50 percent of the total costs of dementia care. ${ }^{7}$

\section{The Burden on Family Caregivers is Unsustainable}

Informal care, which we refer to as family care, is unpaid care that usually consists of assistance from a relative, partner friend, or neighbor. The vast majority of dementia LTSS are provided by family caregivers, as much as 80 percent by one estimate. ${ }^{8}$ More than 15 million Americans currently provide care to family members or friends with dementia. ${ }^{9}$ These family caregivers shoulder a heavy burden; nearly 40 percent reported quitting jobs or reducing work

\footnotetext{
${ }^{5}$ Hurd et al., 2013.

${ }^{6}$ Hurd et al., 2013.

${ }^{7}$ Hurd et al., 2013.

${ }^{8}$ L. Harris-Kojetin, Sengupta, M., Park-Lee, E., and Valverde, R., Long-Term Care Services in the United States: 2013 Overview, Hyattsville, Md.: National Center for Health Statistics, 2013.

9 Alzheimer's Association, “2013 Alzheimer's Disease Facts and Figures," Alzheimer's \& Dementia: the Journal of the Alzheimer's Association, Vol. 9, No. 2, 2013, p. 208-245.
} 
hours to care for a family member or friend with dementia. Many of these caregivers also experience negative physical and mental health effects. At the same time, family caregivers often report being inadequately educated about the trajectory of dementia and the scope of available respite/adult day care resources that could alleviate the stressors of providing care, even one year after a dementia diagnosis has been made. ${ }^{10}$

Demographic trends suggest that the current heavy reliance on family caregiving is unsustainable. Our RAND research has shown that compared to cognitively normal adults, persons living with dementia or cognitive impairment are more likely to receive care from daughters. ${ }^{11}$ This is alarming on several fronts: family sizes are shrinking, the number of women in the labor force is growing, ${ }^{12}$ and women are more likely than men to suffer negative employment and health consequences associated with family caregiving for dementia. ${ }^{13}$ As the median age of the U.S. population continues to trend upward, there will be a growing imbalance between the number of people needing care and family caregivers available to deliver it. ${ }^{14}$ These changes suggest that in the future, more people living with dementia will need to turn to formal care in lieu of or in support of family caregiving.

\section{Public Programs Cover Some Costs, but the Middle Class is Most Vulnerable}

With respect to formal LTSS, Medicaid is the largest payer. ${ }^{15}$ Medicaid can cover skilled nursing facility care and paid care provided in the home or community, as well as assistance with personal care. In contrast, Medicare covers only hospice costs and a portion of short-stay, postacute care for Medicare beneficiaries. Medicaid eligibility rules in many states require that individuals have assets no greater than $\$ 2,000$, and this restriction results in significant gaps in risk protection from LTSS costs. People with adequate resources who plan early enough turn to private long-term care (LTC) insurance or out-of-pocket resources for financing, while lowerincome individuals are covered through Medicaid. The middle class is at greatest risk for

\footnotetext{
${ }^{10}$ M. L. Laakkonen, Raivio, M. M., Eloniemi-Sulkava, U., Tilvis, R. S., and Pitkälä, K. H., "Disclosure of Dementia Diagnosis and The Need for Advance Care Planning in Individuals with Alzheimer's Disease," Journal of the American Geriatrics Society, Vol. 56, No. 11, 2008, pp. 2156-2157; and Allison K. Gibson and Keith A. Anderson, "Difficult Diagnoses: Family Caregivers' Experiences During and Following the Diagnostic Process for Dementia," American Journal of Alzheimer's Disease and Other Dementias, Vol. 26, No. 3, 2011, pp. 212-217.

${ }^{11}$ Esther M. Friedman, Regina A. Shih, Kenneth M. Langa, and Michael D. Hurd, "US Prevalence And Predictors Of Informal Caregiving For Dementia," Health Affairs, Vol. 34, No. 10, 2015, p. 1637-1641.

12 Jonathan Vespa, Jamie M. Lewis, and Rose M. Kreider, “America’s Families and Living Arrangements: 2012," in Current Population Reports 2013, Washington, D.C.: U.S. Census Bureau, 2013.

${ }^{13}$ Family Caregiver Alliance National Center on Caregiving, "Fact Sheet: Caregiver's Guide to Understanding Dementia Behaviors," web page, 2016; and Erin DeFries Bouldin and Elena Andresen, Caregiving Across the United States: Caregivers of Persons with Alzheimer's Disease or Dementia in 8 States and the District of Columbia, Data from the 2009 \& 2010 Behavioral Risk Factor Surveillance System, McLean, Va.: Alzheimer's Association, 2014.

${ }^{14}$ Donald Redfoot, Lynn Feinberg, and Ari Houser, "The Aging of the Baby Boom and the Growing Care Gap: A Look at Future Declines in the Availability of Family Caregivers," in Insight on the Issues, Washington, D.C.: A.P.P. Institute, 2013.

${ }^{15}$ Carol V. O'Shaughnessy, The Basics: National Spending for Long-Term Services and Supports (LTSS) 2013, Washington, D.C.: National Health Policy Forum at George Washington University, 2013.
} 
significant and possibly catastrophic LTSS costs, given the lack of readily available resources to finance their dementia LTSS.

\section{Medicare Post-Acute and Hospice Benefits Are Limited and Differentially Affect Those with Dementia}

Persons with dementia would benefit from the expansion of several Medicare eligibility requirements. First, traditional Medicare covers skilled nursing facility care, if needed after a hospital stay, for patients who are hospitalized for at least three consecutive days. However, patients who are placed under observation status are not considered hospitalized. ${ }^{16}$ Therefore, individuals who have been hospitalized for three consecutive days but under observation for some or all of their hospital stay would not meet the three-day inpatient hospitalization requirement for subsequent skilled nursing facility coverage, thus incurring significant out-ofpocket financial costs. Additionally, some individuals who require intensive health and therapeutic services after a hospitalization may prefer to receive care in their community rather than at a skilled nursing facility. Adult day services are emerging as a key community-based provider of short-term rehabilitation and transitional care following hospital discharge and could provide some specialized services for people living with dementia who have been discharged from a hospital stay, instead of a skilled nursing facility. Under current Medicare policy, however, such community-based care is not reimbursable.

Second, Medicare home health benefits currently require a beneficiary to be deemed "homebound" in order to access covered in-home care. Yet, while persons living with dementia may not always have physical limitations that make them homebound, their mental and other functional limitations may still require the same level of in-home care.

Third, the lifetime course of dementia symptoms can be characterized by long periods of stability punctuated by steep declines and occasional recovery. The average length of stay for beneficiaries with dementia who are receiving Medicare hospice care in skilled nursing facilities has increased over time, ${ }^{17}$ and the per-person hospice care payments across all beneficiaries with dementia were ten times higher than average per-person hospice payments for other Medicare beneficiaries. ${ }^{18}$ At the same time, the ability of physicians to predict six-month mortality for persons with dementia is constrained by great variation in decline and recovery. ${ }^{19}$ Medicare

\footnotetext{
${ }^{16}$ Centers for Medicare \& Medicaid Services, “Chapter 8: Coverage of Extended Care (SNF) Services Under Hospital Insurance," in Medicare Benefit Policy Manual, Baltimore, Md.: Centers for Medicare \& Medicaid Services, 2014.

${ }^{17}$ Susan C. Miller, Julie C. Lima, and Susan L. Mitchell, "Hospice Care for Persons with Dementia: The Growth of Access in US Nursing Homes," American Journal of Alzheimer's Disease and Other Dementias, Vol. 25, No. 8, December 2010, pp. 666-673; Centers for Medicare \& Medicaid Services, 2014.

18 Julie Bynum, tabulations based on data from the Medicare Current Beneficiary Survey for 2008, Dartmouth Institute for Health Policy and Clinical Care, Dartmouth Medical School, November 2011.

${ }^{19}$ Susan L. Mitchell, Susan C. Miller, Joan M. Teno, Roger B. Davis, and Michele L. Shaffer, "The Advanced Dementia Prognostic Tool: a Risk Score to Estimate Survival in Nursing Home Residents with Advanced Dementia," Journal of Pain and Symptom Management, Vol. 40, No. 5, November 2010, pp. 639-651; Susan L. Mitchell, Joan M. Teno, Susan C. Miller, and Vincent Mor, "A National Study of the Location of Death for Older Persons With Dementia," Journal of the American Geriatrics Society, Vol. 53, No. 2, 2005, pp. 299-305; and Greg
} 
currently requires a six-month prognosis in order to qualify for hospice care, but this may not be easy to determine for those in the late stages of dementia.

\section{Policy Options for LTSS and Dementia}

Given the mounting toll dementia will place on our nation's families, LTSS, and health care systems, RAND interviewed 40 stakeholders across seven groups (patients/public, providers, purchasers, payers, policymakers, product makers, and principal investigators), representing multiple perspectives on dementia care, research, and policy, to identify potential policy options. The RAND dementia blueprint reports the independent evaluation of the policy options across 14 feasibility and impact criteria, ultimately arriving at 25 high-impact policy options. For the purposes of this hearing, I discuss the high-impact policy options in that report related to Medicare and those that could aid family caregivers.

\section{Support Family Caregivers}

Family caregivers face a host of challenges caring for loved ones, and the federal government could implement new, or improve existing programs to assist these caregivers.

One option could be to offer business and individual tax incentives to provide family caregiving. This approach could include tax breaks for individuals who are family caregivers, which would provide some compensation for their caregiving time. The incentives could also target businesses to promote provision of adult day care centers on site, expansion of dependent care accounts to incorporate more LTSS costs, and more paid time off and/or flexible work hours to allow for more and varied caregiving

Another option would be to expand financial compensation programs to family caregivers. The RAND dementia blueprint report recommends increasing the availability of compensation programs for lost wages and caregiving work (e.g., through Medicaid programs) and expanding these programs to all states. Such programs are often referred to as "participant-directed services" or "cash and counseling." While some persons with dementia may already have access to these programs, they are not available in all states and are restricted to persons with limited assets (primarily those on Medicaid). This solution would expand access to such programs to subsets of the population who currently cannot access them and increase awareness of existing compensation programs among those who are already eligible.

A third option is to provide dementia-specific training and information about resources to family caregivers and volunteer groups. Interventions aimed at providing dementia-specific education, skill training, support, and counseling to family caregivers have successfully deferred skilled nursing facility placement for persons with dementia and decreased depression and distress among caregivers. ${ }^{20}$ Additional training and information could be provided to volunteer

A. Sachs, Joseph W. Shega, and Deon Cox-Hayley, "Barriers to Excellent End-of-life Care for Patients with Dementia," Journal of General Internal Medicine, Vol. 19, No. 10, 2004, pp. 1057-1063.

${ }^{20}$ M. S. Mittelman and S. J. Bartels, "Translating Research Into Practice: Case Study Of A Community-Based Dementia Caregiver Intervention," Health Affairs, Vol. 33, No. 4, 2014, pp. 587-595; K. Hepburn, Lewis, M., Tornatore, J., Sherman, C. W., and Bremer, K. L., “The Savvy Caregiver Program: The Demonstrated Effectiveness 
groups with access to persons with dementia and family caregivers, so that these groups may be better informed about the needs of persons with dementia. We also recommend wide dissemination of educational materials about providing care, hands-on training, and availability of formal LTSS resources available to family caregivers (e.g., respite care, community services) that may help make caregiving easier and more manageable. Combined, these policy recommendations are likely to reduce caregiver burden and potentially lessen or delay individuals' reliance on formal care often paid for by the federal and state governments. The legal and political feasibility of the option to expand financial compensation programs is likely to be higher than the option to provide tax incentives because the latter involves high costs to the federal government and businesses. Ideally, all three options would be packaged together, so that policies to provide monetary incentives to provide family care would be coupled with LTSS and dementia-specific LTSS training for family caregivers.

\section{A Comprehensive National Financing Solution is Needed for LTSS}

As already discussed, the costs posed by dementia are only going to increase in the coming years, and many families are ill prepared to face those costs. A broad LTC insurance solution is needed to address high out-of-pocket costs for LTSS and the high proportion of older adults afflicted with dementia, and the federal government could help craft a national solution.

One option would be to create a national, voluntary opt-out LTC insurance program through a public-private partnership, which would build upon the structure of the private health insurance system, while having a public wraparound of secondary insurance. Insurance provided by the private LTC insurance industry allows for market competition and consumer choice. Making the program opt-out would encourage greater uptake, which in turn could encourage more private insurers to enter the LTC insurance market. A large insurance pool would limit exposure to the insurers and also improve efficiency by reducing overhead and underwriting risk.

Another option would be to adopt a national single-payer LTC insurance system that is financed through taxes and provides coverage for all citizens. The LTSS benefit could be a basic package or a comprehensive coverage built into Medicare or a new program. While LTC insurance coverage would be funded through the government, services could be provided by private organizations or other contractors.

While both of these options would increase LTSS access and utilization, they also face challenges. Such programs would require substantial implementation costs, creating a significant practical as well as political barrier. I note that both the Commission on Long-Term Care's 2013 report and the alternative report by the dissenting members agreed that an element of public financing is needed, but they disagreed on the extent to which a social LTSS insurance system

of a Transportable Dementia Caregiver Psychoeducation Program," Journal of Gerontological Nursing, Vol. 33, No. 6, 2007, pp. 30-36; and S. Belle, Burgio, L., Burns, R., Coon, D., Czaja, S. J., Gallagher-Thompson, D., Gitlin, L. N., Klinger, J., Koepke, K. M., Lee, C. C., Martindale-Adams, J., Nichols, L., Schulz, R., Stahl, S., Stevens, A., Winter, L., Zhang, S., and Resources for Enhancing Alzheimer's Caregiver Health II Investigators, "Resources for Enhancing Alzheimer's Caregiver Health (REACH) II Investigators: Enhancing the Quality of Life of Dementia Caregivers from Different Ethnic or Racial Groups: A Randomized, Controlled Trial," Annals of Internal Medicine, Vol. 145, No. 10, 2006, pp. 727-738. 
should be publicly financed. ${ }^{21}$ Future quantitative analyses that examine different financing options for public programs, tax credits for saving for LTSS costs, and private LTC insurance will inform the development of a comprehensive LTC insurance program. This is especially critical given the expected rise in dementia prevalence and associated high costs of care to the federal government and families.

\section{Refine Medicare Post-Acute Care and Hospice Benefits}

Medicare post-acute and hospice benefits are limited, and persons with dementia would benefit from the expansion of eligibility requirements. The following options could be considered.

- Refine the three-day hospital stay requirement for skilled nursing facility care. This would extend coverage for skilled nursing facility care by allowing outpatient observation days to count toward the three-day inpatient hospitalization stay required before skilled nursing facility care is covered.

- Allow payments for adult day care instead of a skilled nursing facility. For beneficiaries who prefer to go home after a hospitalization rather than to a skilled nursing facility, Medicare could cover some specialized adult day care services at potentially lower cost than through a skilled nursing facility.

- Expand eligibility of hospice benefits to include dementia as a qualifying event. This change would mean that persons with dementia could receive hospice care before they are diagnosed as terminally ill with a life expectancy of six months or less. Doing so would give persons with dementia more options for palliative care.

- Reconsider the homebound requirement for receiving home health services under Medicare. Expanding eligibility to consider persons with dementia as homebound would allow persons with dementia to have access to in-home care and would help them remain at home longer.

Expansion of these Medicare eligibility criteria for benefits and qualifying events would likely increase LTSS availability and use. Patient safety and patient and caregiver satisfaction would also likely increase with more access to post-acute care. While these recommendations would increase Medicare costs, they may be offset by savings to Medicaid and out-of-pocket spending for potential future LTSS, such as institutionalized care. Future cost analyses could further quantify the implications of these policy options on costs to Medicare.

I appreciate the opportunity to provide a statement for the record for today's hearing. I would be happy to answer any follow-up questions that may arise in response to this statement.

\footnotetext{
${ }^{21}$ Commission on Long-Term Care, Report to the Congress, Washington, D.C.: U.S. General Accounting Office, September 30, 2013; and Long-Term Care Commission, A Comprehensive Approach to Long-Term Services and Supports, Washington, D.C.: U.S. General Accounting Office, September 23, 2013.
} 